\author{
Urška Perenič \\ Filozofska fakulteta, Ljubljana \\ DOI: 10.4312/SSJLK.57.63-70
}

\title{
Prispevek Luize Pesjak h konstituiranju slovenske kratke pripovedne proze
}

V prispevku ${ }^{1}$ najprej očrtamo dogajanje na področju slovenske pripovedne proze. Nato se osredotočimo na začetni pripovedi nemško-slovenske ustvarjalke Luize Pesjak (1828-1898) Očetova ljubezen in Dragotin, obe iz leta 1864. V avtoričinem opusu imata posebno mesto, saj pomenita uresničitev njene namere, da bi bila ne samo nemško, temveč tudi slovensko pišoča domoljubna pisateljica. Pokažemo, kako avtorica z njima po eni strani sledi dominantnim težnjam v konstituiranju slovenskega pripovedništva, po drugi strani pa opozorimo na nekatere novosti. Odtod je mogoče bolje ovrednotiti njen prispevek, saj se je pripovedna proza programsko in kot množična dejavnost začela vzpostavljati prav v šestdesetih letih 19. stoletja. Podamo zasnutek tipologije glavnih značilnosti (začetnega) pripovedništva Luize Pesjak.

19. stoletje, 1864, Kmetijske in rokodelske novice, Slovenski glasnik, slovenske pisateljice, Bled, Selška dolina, motiv starševske ljubezni, domoljubje, avtobiografskost

The paper begins with an outline of Slovene narrative prose and then focuses on the initial narrative texts of the German-Slovene writer Luiza Pesjak (1828-1898): Očetova ljubezen (A Father's Love) and Dragotin, both from 1864. These works have a special place in the writer's oeuvre, for they are a realisation of her intention to be not merely a German, but more a Slovene-writing patriotic author. Attention is drawn to how the writer followed the dominant tendencies in constituting Slovene narrative, but some new approaches are also revealed. It is then easier to evaluate her contribution, for narrative prose only became programmatic and widespread in the 1860 s. A draft typology is offered of the main characteristics of the (early) narrative writing of Luiza Pesjak.

$19^{\text {th }}$ century, 1864, Kmetijske in rokodelske novice, Slovenski glasnik, Slovene female writers, Bled, Selca Valley, motif of parents' love, patriotism, autobiographical features

\section{Slovenska pripovedna proza med 1836 in 1864}

\subsection{Kratek pregled}

V razvoju slovenske pripovedne proze domača literarna zgodovina veliko pomembnost, utemeljeno na vsebinski in/ali izrazni inovativnosti, priznava izbranim delom. Med njimi sta najprej poučnovzgojna povest Sreča v nesreči Janeza Ciglerja $(1836)^{2}$ in tip kratke pripovedi, kakršno so pisali vajevci. ${ }^{3}$ Omenimo prototipski »značajski noveli« Tilka in Jeprški učitelj Simona Jenka, ki v središče postavljata lik posebneža s tragikomično usodo in sta obe iz leta 1858. To je hkrati letnica izida

1 Prispevek je nastal v okviru raziskovalnega programa P6-0239, ki ga je sofinancirala Javna agencija za raziskovalno dejavnost Republike Slovenije iz državnega proračuna.

2 Od sredine štiridesetih do sredine petdesetih let 19. stoletja je vse več objavljenih pripovedi, ki večidel ostajajo na obrobju nacionalnega kanona ali zunaj njega. Omenimo Franca Malavašiča in njegovo besedilo Erazem iz Jame (1845), ki bi lahko bilo prva slovenska zgodovinska povest, Janeza Trdino in njegove Narodne pripovedke iz Bistriške doline, pripovedko Arov in Zman in Pripovedko od Glasan-boga (1849/50) ter kratke pripovedi Josipine Turnograjske, ki je največ tematizirala folklorno in zgodovinsko snov (Kocijan 1983: 61-74).

3 Iz kroga vajevcev na področju kratkega pripovedništva (in pod vplivom poetike realizma) od 2. polovice petdesetih let ustvarjajo Valentin Mandelc, Valentin Zarnik, Fran Erjavec (Kocijan 1983: 74-78; Paternu 1989: 73-). Njihov sodobnik je bil Janez Mencinger. 
Jenkove pripovedi Spomini, pripovedi Jela izpod peresa Valentina Mandelca ter literarnega programa Popotovanje iz Litije do Čateža, v katerem je skušal Fran Levstik slovenske ustvarjalce preusmeriti od pesništva k pripovedništvu. Sam ga je deloma uresničil skozi pripovedko Martin Krpan z Vrha (vse našteto je izšlo istega leta v Slovenskem glasniku v Celovcu). V prvi polovici šestdesetih let je stopil na prizorišče tedaj niti 20-letni Josip Jurčič (s prvencema Spomini na deda in Prazna vera, 1863), ki je zares prodrl s turško povestjo Jurij Kozjak, slovenski janičar (1864), za katero so ga pri Mohorjevi družbi nagradili, 4 in je kmalu postal najpomembnejši tvorec slovenske zgodovinske povesti oziroma romana. Ravno $v$ tej dobi je $v$ slovenščini nastopila - prej samo nemška in poslej dvojezična ustvarjalka - Luiza Pesjak.

\subsection{Rast prozne produkcije in daljšanje pripovedi}

Ko spremljamo razvoj pripovedne proze v slovenščini, lahko opazimo dvoje reči. Na eni strani gre za vse večji kreativni angažma slovenskih besednih ustvarjalcev. Kaže se v rasti števila objav $v$ slovenščini, kar je zlasti v odvisnosti od eksponentne rasti slovenskega časopisja in razvijajoče se meščanske javnosti. Na drugi strani zaznamo težnjo po daljšanju pripovedi oziroma premikanje od obsegovno krajšega in pretežno vaškega tipa pripovedi (zanjo je najbolj zaslužen Josip Jurčič, za njim izmed klasikov navedimo Janka Kersnika, Josipa Stritarja, Ivana Tavčarja) k vse daljši pripovedi (kmečkega in zgodovinskega žanra). Taka teksta sta npr. Jurčičev Deseti brat (1866) in njegova povest Sosedov sin (1868) (prim. Paternu 1974; Kocijan 1978; Hladnik 1982; Kos 1984). V obdobju po letu 1870 se poveča »[p]estrost proznih žanrov« (Dović 2007: 117).

To je strnjena podoba dogajanja na področju slovenskega pripovedništva okrog sredine 19. stoletja, v katerega se je tvorno vključila Luiza Pesjak. Pokazali bomo, kako je s svojimi začetnimi (in ne nujno začetniškimi) pripovedmi po eni strani sledila prevladujočim »trendom « v razvijajočem se domačem pripovedništvu (med njegovimi potezami izpostavimo vezanost na folklorno-kmečko snov, postopno tematiziranje meščanskega življenja, s čimer se skozi čas spreminja tudi namembnost literature, ki gre od preprostejšega k bolj izobraženemu naslovniku, ter narodnoafirmativno funkcijo), po drugi strani pa, kako je pomagala v vsebinskem in izraznem smislu bogatiti tedanjo slovensko književnost. Začetno ustvarjalnost Luize Pesjak bomo ovrednotili še v perspektivi njenega poznejšega pripovednoproznega pisanja ter poskušali podati tipologijo temeljnih značilnosti njenega kratkega pripovedništva.

\section{Vstop Luize Pesjak v slovensko književnost: leto 1864}

Luiza Pesjak je v slovensko književnost kot pesnica vstopila programsko. Spomnimo, da je svojo ustvarjalno pot pričela kot nemška pesnica, stara dobrih 15 let (najstarejši pesniški poizkusi so iz let $1843 / 44){ }^{5}$ To ni nehala biti niti pozneje, saj je od šestdesetih let in praktično do konca življenja objavljala v nemških listih (v Avstriji in na Nemškem), dokler ni leta 1885 izdala nemško pesniško zbirko za otroke Ins Kinderherz. ${ }^{6}$ Vendar je v šestdesetih letih ravno tako in odtlej vse

4 Iz leta 1863 je povest Frana Erjavca Huzarji na Polici, Josip Jurčič je 1864 objavil še povest Domen.

5 Za več o slovenski narodni motiviki pri Pesjak prim. Perenič 2006b.

6 V zapuščini je tudi neobjavljena nemška zbirka za otroke in mladino Zwischen Moos und Tannenzweigen, ki jo je posvetila enemu od vnukov. 
več objavljala v slovenščini, ${ }^{7}$ najprej pesmi, kmalu še prozo, pa spet in praktično skozi trideset let pesmi v več slovenskih časopisih, kot so Kmetijske in rokodelske novice, Slovenski glasnik, Kres, Besednik, Zvon in Ljubljanski zvon.

25. 5. 1864 je v Kmetijskih in rokodelskih novicah izšla pesem Kar ljubim, ki jo je na dan sv. Feliksa podpisala »Lojza Pesjakova«. Pesem ima nadnaslov Prva moja pesmica slovenska, nastala pa naj bi pri pouku slovenščine, ki se je je začela učiti skupaj s petimi hčerami in pod mentorstvom Antona Lesarja v šestdesetih letih 19. stoletja (Koblar 1935). Urednik Novic Janez Bleiweis je objavo pospremil z besedami: "Dobro došla pesmica mila! Prosimo večkrat kaj." Miran Hladnik (2005) piše, da je šlo za deklarativni vstop v slovenski kulturni krog, kar je eksplicitno izraženo v zaključnih verzih druge od dveh osemvrstičnic: "Ljubim Sloven'jo, ji roko podam, / Bog jo potrdi, in živi jo nam!« Vendar bi bilo ob upoštevanju dejstva, da je vse življenje objavljala v obeh jezikih, morda namesto o vstopu v slovenski krog še ustrezneje govoriti o jasno izraženi nameri, da bi postala tudi slovensko (in torej ne samo nemško) pišoča domoljubna pesnica in pisateljica.

Istega leta sta namreč v Kmetijskih in rokodelskih novicah in v Slovenskem glasniku izšli njena »novela« Očetova ljubezen ter [povestica] Dragotin. Očetova ljubezen je nekakšen pendant pesmi Kar ljubim, saj predstavlja ne samo prvo prozno objavo v slovenščini, ampak se z njo sklada tudi v sporočilnosti, ki je domoljubna, slovenska. Potem ko je Luiza Pesjak slovenskim rojakom že simbolno podala roko v pesništvu, enako stori v pripovedništvu. Dragotina je Slovenski glasnik objavil sredi jeseni istega leta (pred tem se je njegova avtorica bralcem predstavila z nekaj aforizmi v slovenščini). Sicer samo za obdobje šestdesetih let 19. stoletja v slovenski periodiki naštejemo prek 30 večinoma izvirnih objav Luize Pesjak, ki izpričujejo izjemen kreativni angažma pri vstopanju na slovenski parnas.

\section{Očetova ljubezen: Novela in Dragotin}

V prispevku izhajamo iz naslednjih izhodišč. Prvič, začetni pripovedi Luize Pesjak se navezujeta na sočasno pripovedništvo v slovenščini, kar se zlasti kaže v izbiri rodoljubnih motivov in narodnopotrjevalnem stališču. Drugič, pripovedi se hkrati odmikata od sočasne (moške) ustvarjalnosti, kar najprej opazimo v drugačni izbiri in obdelavi nekaterih motivov. Tak je npr. motiv starševske ljubezeni, ki je izražena v naslovu in preraste tudi v osrednjo temo. Tretjič, v širši perspektivi konstituiranja slovenske književnosti ter ožji perspektivi razvoja avtoričine izvirne proze, kjer začetnima pripovedma sledijo še pripovedi Rahela (Pesjak 1870), Moja zvezdica (Pesjak 1871) in roman Beatin dnevnik (1887), pa Dragotin in Očetova ljubezen predstavljata logično (in nujno) razvojno stopnjo. Ugotovimo, da v vsebinskem oziroma sporočilnem smislu nadaljujeta avtoričino domoljubno pesniško ustvarjalnost, zraven pa že nakazujeta naslednje stopnje ustvarjanja. Na področju proznega pisanja napovedujeta daljši pripovednoprozni tekst (roman Beatin dnevnik bo avtoričino zadnje in najdaljše besedilo v slovenščini). Zraven razberemo težnjo po vse večji vrstno-žanrski pestrosti, ki se kaže v prehojeni poti od novelice prek povestice do romana.

7 Pesniška prizadevanja v slovenščini je okronala z zbirko za otroke Vijolice (1889). 


\subsection{Očetova ljubezen}

Na domoljubno naravnanost kratke pripovedi je opozoril že France Koblar (1935), ki je povzel, da Luiza Pesjak v njej popiše »lepoto domače zemlje (Bled). « $V$ »noveli« si uvodoma in drug za drugim sledijo domoljubni motivi. To so Blejsko jezero, ki ga imenuje okras domovine (v besedilu je primerjan s "prežlahtnim kamnom «, je poosebljen in ogovorjen), Blejski otok s cerkvico [Marijinega vnebovzetja] ter "orjaški« Triglav. Sredi 19. stoletja sta bila tako Triglav kot Bled že prepoznavna simbola slovenstva. ${ }^{8}$ Pisateljica je na ta način ustvarila ne samo vzneseno in idilično sliko domačega gorenjskega prostora, temveč predvsem izrazito domoljubni incipit, ki ima v kompoziciji dela važno funkcijo. Z njim je namreč dogajanje eksplicitno umestila na Slovensko. Ni mogoče spregledati povezanosti pripovedovalca oziroma pripovedovalke s tem »mitskim« prostorom slovenstva.

Bleško jezero! ti prežlahtni kamen v dragotinah stvarstva, preslavni kinč lepe naše domovine - čisto ko zrcalo se sprostiraš med cvetličnimi obrežji, in kakor veščasta marnja se vzdiga iz tvojih valov mični otok $\mathrm{s}$ cerkvico, v katero nas vabi milostljiva podoba nebeške device. Očitna slika vzvišanosti, ktera se lepoti nasmehljuje, je orjaški Triglav, ki te prijazno pozdravlja z vrtoglavno svojo višavo. Srce se segreje ogledovaje tebe, svetlo jezero, in v tvoji bližavi se čuti brezkončna ljubezen Božja, ktera se tukaj čudapolna razodeva, tukaj, kjer cela narava le sope ljubeznost in prijaznost. (Pesjak 1864a: 217)

Omenjena povezanost je razvidna tudi v subjektiviziranem in liriziranem opisu "čudapolne" narave, ki se povezuje z občutenjem Božje bližine. To bo postalo eno od prepoznavnih razpoloženj $v$ tako rekoč vseh pripovedih Pesjakove (in pri moških sodobnikih v taki obliki nanj ne naletimo), ${ }^{9}$ torej tudi v Dragotinu in slednjič Beatinem dnevniku. ${ }^{10}$

Odmik in po tej poti vsebinsko bogatitev sočasnega pripovedništva pomeni pisateljičina izbira ali bolje rečeno obdelava motiva starševske ljubezni, konkretno med očetom in hčerko, ki prerašča v eno osrednjih tematskih polj in se povezuje s temo domoljubja. V središču "novele« je zgodba ribiča-čolnarja Janeza, ovdovelega očeta štirih deklic, ki »vedil je národne pesmi lepo popevati, in butanje valov in pravilni udar njegovega vesla sta skladno spremljala sladke gorenske viže." (Pesjak 1864a) Tako mora Janez po priprošnji Devici Mariji nazadnje zavrniti prošnjo tuje bogate gospe ob obisku Bleda, da bi ji dal hčerko in s tem omogočil, da vsaj nekoliko okusi radost materinske ljubezni.

Prek lika bogate tujke, ki prihaja »od kraja jadranskega morja«, se v »noveli« obenem oblikuje opozicija med domačim in tujim, kar je še ena od poudarjenih značilnosti v pripovedih Luize Pesjak in ima domoljubno motivacijo.

8 Za več o slovenski narodni motiviki pri Luizi Pesjak prim. Perenič 2006b, za motiviko Bleda pa diplomsko nalogo Mine Černe (2013) Bled v slovenski literaturi »dolgega 19. stoletja«.

9 Ubeseditev tega občutja je malone identična liriziranemu opisu iz pisateljičinega nemškega intimnega dnevnika, kjer mladenka Luiza ob obisku gradu Snežnik na Notranjskem tenkočutno popiše veslanje po Cerkniškem jezeru (Perenič 2019a: 17). Izmed starejših književnih ustarjalcev pa v tem kontekstu spomnimo na pesem Vršac Valentina Vodnika.

10 Naravo (tisočletni gozd in snežnike) prispodablja s templjem in oltarjem, kjer uporabi motiviko večnega snega ter barvno metaforiko ognja in mavrice: Oh! - - kakó mirno in slovesno, kakó čudovito! Veličastno se razprostira pred pogledi mojimi tisočletni gozd in snežniki se vzdigujejo za njim, kakor visok oltar, ki seza v oblake, podprt z granitnimi svojimi stebri! Solnce blesti na večnem snegu in ga izpreminja v bôje ognja in mávrice. Mrak se polega krog, gozd se temí, ali gôri je še demantna svetloba! Baš zahaja solnce na drugi stráni doline za d...kim vrhom in snežniki so rožnati in žaré v čarovni krasoti. Tiho je vse, pokoj plava po vzduhu, pokoj biva na zemlji. (Pesjak 1887) 
Doživetje topline doma, ki je tako odraz močnih čustvenih in duhovnih vezi med člani družine kakor navezanosti na domači prostor in zemljo, pisateljica doseže tudi tako, da bralca spretno in sugestivno popelje v interier doma. Izstopajo motivi mize, okrog katere se zbira družina, klopi in materinega kolovrata, na katerem se še čutijo njene roke. Po čolnarjevi čedni izbi se takole razgledamo skozi oči bogate gospe:

Primerilo se je, da neko jutro gospá hotla se je k maši na otok peljati, in stopila je v ribičevo hišo iskaje čolnarja. Janeza bilo ni domá, pa gospá stopivši v čumnatico ostrmí pred podobo, ki jo zagledajo njene očí. Solnčni žarki so vsipali se skoz ozko oknice in zlatili so revno, toda čedno izbo. Javorjeva miza in dve klopi so stale v kotu in celo do stropa visele so podobe svetnikov, kinčane s pisanim papirjem. Pod podobami v voglu zida pribita je bila leséna diljica pokrita $s$ snegobelo ruto, $v$ katero bile ste vezani imeni Jezusa in Marije; na diljici brlela je lampica na čast Materi Božji in zraven svetilnice ležale so molitvene bukve in rožni venec preljube rajne matere. Tudi kolovrat stal je pri sedalu in preja njena bila je še na vretenu; ko svetinje varoval je Janez opomine nepozabljive žene. (Pesjak 1864a)

Pisateljica se takó na izvirne načine in s hkratnim navezovanjem na sočasno ustvarjanje (podčrtajmo njeno umeščanje dogajanja v geografsko prepoznaven in domači prostor, uporabo prepoznavne narodne motivike ter izvirno obdelavo motiva starševske ljubezni) vključuje v proces konstituiranja slovenske proze. Njeno pisanje v vsebinskem in idejno sporočilnem smislu pušča podoben vtis kot preostalo prozno ustvarjanje, ne da bi spregledali nekatere slogovne (npr. subtilna lirizacija) ${ }^{11}$ in motivne izvirnosti. Podobno kot moški sodobniki se sama skozi čas nagiba $k$ vse daljši pripovedi.

\subsection{Dragotin}

V Dragotinu, ki ga je France Koblar (1935) z nekoliko pejorativnim prizvokom označil kot »domoljubno povestico« (deminutiv najbrž meri na njen obseg), na začetku sicer ni določnejšega zarisa dogajalnega prostora, vendar je struktura vsebine podobna, saj je avtorica uporabila domoljubni moto. Ta ima v kompoziciji besedila vlogo nekakšnega okvira in kaže na zvezanost pripovedovalke z domačim prostorom, kar je eksplicirano v pozivu k ljubezni do »dežele materne«. ${ }^{12}$

Te ljubim, ko solnce žarivno bliščí,

Te ljubim, ko luna na nebu svetí;

Te ljubim, ko rože premilo cvetó,

Te ljubim, ko cvetja ne vidi okó;

Te ljubim, ko sreča mi greje srcé,

Te ljubim, ko britke prelivam solzé;

11 Ta bi bila sicer lahko tudi razlog za očitek, da ostaja s svojim pisanjem v območju prejšnjega literarnega obdobja romantike.

12 Podobne prijeme je enako uporabila pozneje v »izvirni novelici« Rahela (1870), ki se začne z besedami »Dolina S ..., kjer stoji vas tistega imena«), in v romanu Beatin dnevnik (1887), kjer na začetku beremo: „V graščini Š. 20. dné maja meseca 1875." 
Te ljubim, te pojem, povsod te častim, Dežela mi materna! - za-te gorim. -

(Pesjak 1864a)

Domoljubno čustvo se vnovič povezuje z doživetjem pomladne (rožnate) jutranje svetlobe pred sončnim vzhodom, pri čemer narava prispodablja Božji mir in brezkončnost vesolja.

Kako lep je spomladanjski svet ob zoru, kedar jutranja zarja vse obseva z rožnato svojo svitlobo, kedar se krilati glasnik ranega dneva, veseli škrjanček vzdiga pod visoke oblake in gozdne ptičice budí z žvergolečim svojim petjem, kedar vse, do najmanjšega atoma, začne gibati se in oznanjati radost svojega bitja. Vijolice dihljajo sladko vonjavo, rože žaré in s tisoč in tisoč cveticami si veze mlada zemlja nevestino svojo obleko; v vsaki cvetici miglja žlahni kamen, v kterem se lomijo solnčni žarki, in lepó se podajo rosne te solzice slikam veselja, goršaje jih, kakor se lepša sladka sreča in slavi s solzami britke otožnosti. Pisani metulji frfolé od cveta do cveta, poljubovaje sreberne bisere iz lepo dišečih čašic, marljive bučele unašajo Florinim otrokom najslajši poživek in zamolkli hrošči brenčijo okoli njih v enoglasnem svojem šumenji. Povsod kraljuje veselje in marljivost in vendar je vse pokojno in mirno, kakor da bi Gospod stvarstva sam zdaj in zdaj nevidno prišel in kakor da bi lahke meglice kadila pred njim trosile, cvetice mu venčale pota, ptičice mu himne pele in da bi klasje in gozdi njemu upogibali se. (Pesjak 1864a)

V kmečko hišo, kjer domujeta Dragotin in mati in je opisana na idealiziran način, tu za razliko od »novele« Očetova ljubezen vstopimo proti koncu, saj je prvi del »povestice« namenjen Dragotinovemu potikanju po svetu, da bi se slednjič vrnil v zavetje doma (v epilogu sledi Dragotinovo pismo stricu, v katerem mu sporoča, da bo ostal doma). Vendar je ta opis $v$ strukturi besedila v podobni sporočilni funkciji. Ob nekaterih ponovljenih motivih, kakor so kolovrat, ki so ga imeli v kmečkih hišah, klopi, kmečka peč, sveti križ, je pisateljica uporabila motiv rožmarina z narodno simboliko trdoživosti in ljubezni.

Tiho je vse bilo, po veži je šel in odprl izbo. Zdelo se mu je, da v cerkev stopi in vpognil je skoraj kolena, zagledavši mali, mirni kraj, v kterem je prebivala njegova ljubezen. Vse je še bilo kot popred, prosto tesarsko orodje, velika zelena peč s klopjo, podoba svetega križa v voglu, lonci z rožmarinom, z rutico in z muškatovim cvetjem na malem okencu, in pri oknu je sédela mati, lepa in bleda kot popred, in ko nekdaj ste nježni roki tanko nit sukali, kolovrat pa je brenčal z navadnim glasom. V izbo stopivši Dragotin s trepečim glasom reče: »Hvaljen bodi večni Bog!« - in materno srce na glasu spozna spreljubo svoje déte, zavpije »moj sin« in prevelikega veselja nepremakljiva ostane. Sin pa se ji približa, poklekne na staro podnožnico - in srce bije na srce, bolečine potihnejo, nebesa se odpró. (Pesjak 1864b) ${ }^{13}$

13 V obsežnejšem uvodu v »izvirno novelico« Rahela opis notranjosti hiše graščinskega logarja spet sledi uvodu, ki dogajanje umešča v stvarni geoprostor. Variantno so uporabljeni (simbolni) motivi "snegobelih« prtov oziroma rut, rožmarina, drugi cvetlični motivi, motiv kolovrata. $V$ notranjost, in sicer svoje sobice s pisalno mizo, nas na začetku in po prihodu na graščino popelje tudi pripovedovalka v Beatinem dnevniku. 
Medtem ko je v Očetovi ljubezni upovedena brezpogojna ljubezen očeta do hčerke, je v Dragotinu v ospredju ljubezen med materjo in sinom. Izbira motiva kaže na nove možnosti, ki jih je iskala pisateljica, vendar se enako prepleta z domoljubnim sporočilom. To je okrepljeno še na način opozicije s tujino. Če jo v Očetovi ljubezni zastopa bogata tujka, je to v Dragotinu premožen stric skrinjar, ki zvabi naslovnega junaka na Tirolsko, da bi se učil rokodelstva. Razen slovesa od očeta na vaškem pokopališču (Koblar 1935), ob katerem si Dragotin utrga »bagrenih klinčkov, mičnih potočnic in snegobelih šmarnic « (ni mogoče spregledati rdeče-modro-bele simbolike narodnih barv), je morda še bolj čustven opis njegovega slovesa od matere in domače zemlje obenem. S stricem se usedeta na voz, potem pa ju pot pelje

skoz Česnico, Studeno in Selce do Loke, zmiraj Sori na bregu, in malo po malo se je razširjala dolina, razširjalo obnebje, al zmiraj bolj tesno je bilo pri srcu mlademu popotniku. Molčé je sedel zraven strica, poljubovaje sem ter tje gomiline cvetice in ves zamišljen v materno besedo - ktera mu je bila od nekdaj zapoved - da je za njuno srečo potrebno ločiti se. Stric je vedel ceniti žalost milosrčnega dečka in z mehkimi besedami je včasi skušal bolečine utolažiti mu.

Od Loke sta se peljala po gorenskih krajih na Goratansko, in od tod po pustriški dolini do mestica N...., kamor sta bila namenjena. (Pesjak 1864b)

Peljejo se skozi Selško dolino (Česnik, Studeno, Selca [med Škofjo Loko in Železniki], Škofjo Loko) prek Gorenjske v Pustriško dolino do mesta N., ki najverjetneje referira na Niederdorf.

V tujini Dragotin pogreša »sladk[e] glasov[e] maternega jezika«. Domotožje si skuša blažiti tako, da se zateka v naravo, v gore, ki imajo pri Luizi Pesjak (npr. v Beatinem dnevniku) prepoznavno simboliko svobode. V gorah, ki so obsijane s soncem, se čuti hkrati še bolj povezanega z Bogom.

In kako zamakljiv je pogled na daljne planine in lednike, ktere je Božja roka kot velike oltarje postavila za tempelj naravi. Zeleni plašč, ki obdaja snežnikom noge, je obrobljen na vrhu z večnim snegom in na milijarde dijamantov ga kinča v solnčni svitlobi. Neizrekljivo lepa je ta podoba zvečer, ko jame senca legati nad dolino, ko zadnji žarki zlatijo granitne gače, ki škarlatno, rožasto in vijolično žaré in ko jih naposled luna preobliva s srebernimi potoki. (Pesjak 1864b)

Pisateljica je v »povestico« Dragotin vtkala nekatere avtobiografske elemente, kar pozneje zasledimo v pripovedi Rahela ${ }^{14}$ in Beatinem dnevniku (prim. Perenič 2019). Mislimo na dogajalni prostor Železnikov. Ko se Dragotin na tujem spominja svojega otroštva, izvemo, da je bil njegov oče kovač v Železnikih, ki so domači kraj pisateljičinega očeta, advokata in Prešernovega sodobnika Blaža Crobatha. V besedilu izstopa motiv plavža, kjer gre za najstarejši slovenski plavž, ki so ga okoli 1860 zgradili ravno v Železnikih. S tem je v zgodbo vpleten drobec iz tehnične zgodovine slovenskega prostora (spomnimo, da je Luiza Pesjak tako v slovenske kot nemške pesmi rada vpletala elemente iz slovenske naravne in kulturne dediščine).

14 Mati naslovne junakinje je tako kot pisateljičina mati poljskega rodu. Iz zgodbe izvemo, da je mož njene prijateljice na svoj dom sprejel poljska izgnanca Korytka in Horodynskega, kar pa je dejansko storil pisateljičin oče Blaž Crobath. 


\section{Zaključek}

Začetna (in tudi poznejša) pripovedna proza Luize Pesjak črpa iz svoje vpetosti v slovensko kulturo in slovenstvo. Na ta način se narodnotvorno vključuje $v$ proces konstituiranja pripovedništva v slovenščini, kakršnega pišejo njeni moški sodobniki, ne da bi se odpovedala iskanju lastnih in izvirnih motivnih, tematskih in izraznih možnosti. Med glavnimi tipološkimi značilnostmi njenega pripovednoproznega pisanja, ki jih je $v$ splošnem mogoče potrditi v vsem njenem pripovedništvu, so: umeščanje dogajanja v prepoznaven in domači geografski prostor, prvine subjektivizacije in lirizacije, vključevanje prepoznavne narodne motivike, kjer avtorica črpa iz območij naravne, kulturne in tehnične dediščine slovenstva, izvirne načine obravnave motiva starševske ljubezni ter avtobiografskost. Skozi pretek časa njene pripovedi postajajo vse daljše, dokler leta 1887 ne izide najobsežnejše delo, roman Beatin dnevnik. Ker je v njem uporabila več motivov in prvin, ki jih zasledimo $v$ predhodnih pripovedih, se ponuja teza, da so bile omenjene pripovedi podlaga obsežnejšemu epskemu tekstu. To pa bo predmet naše naslednje razprave.

\section{Viri in literatura}

DOVIĆ, Marijan, 2007: Slovenski pisatelj: Razvoj vloge literarnega proizvajalca v slovenskem literarnem sistemu. Ljubljana: Založba ZRC, ZRC SAZU.

HLADNIK, Miran, 1982: Mohorjanska pripovedna proza. Slavistična revija XXX/4. 389-414.

HLADNIK, Miran, 2009: Slovenski zgodovinski roman. Ljubljana: Znanstvena založba Filozofske fakultete.

KOBLAR, France, 1935: Luiza Pesjak. Slovenska biografija. https://www.slovenska-biografija.si/oseba/sbi417228/

KOCIJAN, Gregor (ur.), 1978: Jurčičeva kratka pripovedna proza. Ljubljana: Mladinska knjiga. 115-135.

KOCIJAN, Gregor, 1983: Kratka pripovedna proza od Trdine do Kersnika. Ljubljana: DZS.

KOS, Janko, 1984: K vprašanju zvrsti v slovenski pripovedni prozi. Primerjalna književnost VI/1. 1-16.

PATERNU, Boris, 1974: Pogledi na slovensko književnost II. Ljubljana: Partizanska knjiga.

PATERNU, Boris, 1989: Obdobja in slogi v slovenski književnosti. Ljubljana: Mladinska knjiga.

PERENIČ, Urška, 2006a: "Poetische Versuche 1843-1844« Luize Pesjak - poskus umestitve dela nemške ustvarjalnosti na Slovenskem v okvir slovenske literarne zgodovine. Slavistična revija LV/2. 233-244.

PERENIČ, Urška, 2006b: Teoretični nastavki v vključevanju nemškega opusa Luize Pesjak v okvir slovenske literarne vede - "...und doch geht es uns an«. Irena Novak Popov (ur.): Mesto in meščani v slovenskem jeziku, literaturi in kulturi. 42. SSJLK. Ljubljana: Center za slovenščino kot drugi/tuji jezik pri Oddelku za slovenistiko Filozofske fakultete. 244-247.

PESJAK, Luiza, 1864a: Očetova ljubezen: Novela. Kmetijske in rokodelske novice XX/27. 217-218.

PESJAK, Luiza, 1864b: Dragotin. Slovenski glasnik VII/11. 327-333.

PESJAK, Luiza, 1870: Rahela: Izvirna novelica. Letopis Matice slovenske. 138-163. https://www.dlib.si/details/URN: NBN:SI:doc-QCHINZ9Q

PESJAK, Luiza, 1871: Moja zvezdica. Letopis Matice slovenske. 320-329. https://www.dlib.si/details/URN:NBN:SI: DOC-TA5DLFCT

PESJAKOVA, Luiza, PERENIČ, Urška, 2019: Beatin dnevnik: Roman, Prvi slovenski družinski roman v obliki dnevnika. Ljubljana: Znanstvena založba Filozofske fakultete. https://e-knjige.ff.uni-lj.si/znanstvena-zalozba/catalog/download/ $151 / 247 / 3842-1$ ? inline=1 